\title{
Wood Particle-Recycled Glass Fiber Hybrid Composites
}

\author{
Kayode E. Oluwabunmi, Lee M. Smith, Sheldon Q. Shi* \\ Department of Mechanical and Energy Engineering, University of North Texas, Denton, TX, USA \\ Email: ^sheldon.shi@unt.edu
}

How to cite this paper: Oluwabunmi, K.E., Smith, L.M. and Shi, S.Q. (2017) Wood Particle-Recycled Glass Fiber Hybrid Composites. Open Journal of Composite Materials, 7, 265-276.

https://doi.org/10.4236/ojcm.2017.75018

Received: July 7, 2017

Accepted: October 24, 2017

Published: October 27, 2017

Copyright $\odot 2017$ by authors and Scientific Research Publishing Inc. This work is licensed under the Creative Commons Attribution International License (CC BY 4.0).

http://creativecommons.org/licenses/by/4.0/

\begin{abstract}
This study was done with the aim of assessing the feasibility of mechanically recycled glass fiber particleboards made from (loblolly pine and longleaf pine) wood particles with epoxy as binder. The modulus of rupture (MOR) and modulus of elasticity (MOE) were evaluated as indicators of mechanical performance. The water absorption rate and thickness swelling rate were also analyzed to investigate the physical performance of the board. An increase of over $80 \%$ in MOE values was obtained for the boards with $10 \mathrm{wt} \%$ glass fiber inclusion. For the MOR values, there was an increase of over $84.4 \%$ in both densities and glass fiber inclusions of all the board densities. However, there was a decrease in MOE when $30 \mathrm{wt} \%$ glass fibers were incorporated into boards with density of $500 \mathrm{~kg} / \mathrm{m}^{3}$ and $700 \mathrm{~kg} / \mathrm{m}^{3}$. A r-squared value of 0.869 supported the obtained result that the correlation between water absorption rate and thickness swelling rate was a function of the density of the composites.
\end{abstract}

\section{Keywords}

Particleboard, Recycled Glass Fibers, Water Absorption, Thickness Swelling

\section{Introduction}

Glass fiber is a special class of materials that is manufactured by the high-temperature conversion of various raw materials (predominantly borosilicates) into a homogeneous melt, followed by the fabrication of this melt into thin fibers. These materials find dynamic applications in human's everyday life, include thermal insulation, automobile parts, pipes and fittings, textiles, construction and more recently for boat making amongst others. The global consumption of textile glass fiber was about 4 million metric tons (Mt) in 2011 [1], 
and it is projected to reach 4.5 Mt in 2018 [2]. However, because recycling through a thermal process could cause about $50 \%$ loss in mechanical properties [3]. The glass fibers would be best recycled through a mechanical process that involves grinding and crushing and then employed for use in manufacturing non-structural products [3]. Products made from glass fibers, especially boats, automobile parts, have increasingly become an environmental menace when they reach the end of their lives. There is a need to find an alternative way to recycle glass fibers. Panel products such as particleboards made from lignocellulosic fibers are available at low cost, easy to recycle and biodegradable. However, they mostly find applications where cost other than aesthetics and strength are major determining factors [4] [5] [6]. After World War II, the manufacture of particleboards began on a large scale in the United States, serving as a low-cost replacement for plywood and lumber in the cabinetry and furniture industry. Seventy years down the line, the demand for particle-boards has grown extensively, replacing plywood and solid wood products. However, particleboard expands and shrinks when the ambient humidity fluctuates, this affects their performance in service negatively [7] [12] [13]. Much research work has been carried out to improve the mechanical and physical properties of wood particleboard using different materials and treatments [7] [9] [10]. Particleboards made from a mixture of wood particles and glass fibers as the core, and two layers of woven jute fabric as skin layers were fabricated using the vacuum-assisted resin transfer molding technique [7]. With this procedure, higher values compared to commercially available hybrid composites were obtained [7] [11]. Particleboards have been developed from wood (Eucalyptus grandis), bamboo (Bambusa vulgaris), and/or rice husk (Oryza sativa) particles [8]. Sorghum bagasse and Compedek wood shaving in $50 \mathrm{wt} \%$ ratio and 10\% urea formaldehyde (UF) resin as binder was used in manufacturing particleboard. Additionally, composite boards have been produced from shavings of southern yellow pine, kenaf and flax all blended together [9]. The highest values recorded for the MOR and MOE were 27.6 $\mathrm{MPa}$ and 4.5 $\mathrm{GPa}$, respectively. Various studies have been carried out to improve the physical and mechanical properties of particleboard using different types of binders.

The objective of this study was to investigate the mechanical and physical properties of particleboards made from a mixture of loblolly pine and longleaf pine wood flour and mechanically recycled short glass fibers using epoxy as binder. The MOE and MOR as well as the swell rate and absorption rate of the samples were calculated and compared using the Shi and Gardner swelling rate and water absorption models.

\section{Experimental Procedure}

The experiment was carried out to investigate the effect of incorporating recycled glass fibers on the MOE, MOR, water absorption and thickness swelling of the particleboards. 


\subsection{Materials}

Wood particles (majorly from loblolly pine and longleaf pine) were supplied by Nature's Broom, Hollandale Mississippi. The wood particles were sieved using a set of sieves to have an idea of the distribution of the particles. Recycled glass fibers were supplied by Eco-Wolf Inc. Edgewater, Florida. The glass fibers were processed to $3 / 4 "$ of short fibers using a grinder (model GM-1211-30 ECO-Grinder ${ }^{\mathrm{TM}}$ ), a $25-\mathrm{mm}$ filter screen in the machine when the material was processed. The source material came from a local boat manufacturer and is post production waste. Epoxy resin used was the West system 105 epoxy resin part 1 the hardener (West system 206) part 2, both were supplied by West Marine [10].

\subsection{Experimental Design}

The effect of the incorporation of recycled glass fiber on the mechanical properties of particleboard made from wood particles, epoxy resin for making particle-board was the aim of the experiment. Two-factorial experimental design was used. Two factors considered were percentages of glass fibers and board density. Nine sets of samples (reinforcement + matrix) were manufactured with 3 replicates. The percentage by weight of glass fiber in each of the sample sets was varied. The resin to hardener ratio was maintained at 2:1 (wt $\% / v)$. The design matrix for the experiment is shown below [10].

\subsection{Fabrication of Wood-Glass Fiber Hybrid Composites}

The mechanical and physical properties of the of the wood particle-glass fiber hybrid composites was compared with that of commercial particleboard samples. The commercially available particleboard consists of three layers. The top and bottom layers were made of fine wood particles with density of about $(0.940$ $\mathrm{g} / \mathrm{cm}^{3}$ ) each, while the middle layer was made of coarser particles with lower density measuring about $\left(0.5 \mathrm{~g} / \mathrm{cm}^{3}\right)$. The layers were mixed with a binder then hot-pressed [10].

Nine batches of samples shown in Table 1 were prepared. The amount of glass fibers needed per sample was calculated based on the dry weight of the particle and mixed with the assorted wood particles. The weight of the wood particles used was a function of the desired density of the composites $\left(0.3 \mathrm{~g} / \mathrm{cm}^{3}, 0.5\right.$ $\mathrm{g} / \mathrm{cm}^{3}$ and $0.7 \mathrm{~g} / \mathrm{cm}^{3}$ ). To achieve this, particle-board samples with a density of $0.3 \mathrm{~g} / \mathrm{cm}^{3}$ with $10 \%$ glass fiber content were fabricated. $151 \mathrm{~g}$ of wood particles with the calculated proportion of recycled glass fibers were mixed with $43.2 \mathrm{~g}$ of

Table 1. Experimental design.

\begin{tabular}{ccccc}
\hline Sample ID & \% Glass fibers & $\begin{array}{c}\text { Density @ 300 } \\
\mathrm{kg} / \mathrm{m}^{3}\end{array}$ & $\begin{array}{c}\text { Density @ 500 } \\
\mathrm{kg} / \mathrm{m}^{3}\end{array}$ & $\begin{array}{c}\text { Density @ 700 } \\
\mathrm{kg} / \mathrm{m}^{3}\end{array}$ \\
\hline 1 & 0 & $\mathrm{~A} 3000$ & $\mathrm{~B} 5000$ & $\mathrm{C} 7000$ \\
2 & 10 & $\mathrm{~A} 30010$ & $\mathrm{~B} 50010$ & $\mathrm{C} 70010$ \\
3 & 30 & $\mathrm{~A} 30030$ & $\mathrm{~B} 50030$ & $\mathrm{C} 70030$ \\
\hline
\end{tabular}


west marine brand of epoxy as binder and $21.6 \mathrm{~g}$ of slow cure hardener. A proportionate measure was made to achieve a density of $0.3 \mathrm{~g} / \mathrm{cm}^{3}$ at $0 \%, 10 \%$ and $30 \%$. Similar process was also repeated for the density values of $0.5 \mathrm{~g} / \mathrm{cm}^{3}$ and 0.7 $\mathrm{g} / \mathrm{cm}^{3}$ at $0 \%, 10 \%$ and $30 \%$. Manual mixing was done in circular barrel with a diameter of $50 \mathrm{~cm}$ to obtain a nearly homogenous mix. After achieving thorough mixing, the mix was transferred to two metal flat plates with dimensions of $(300 \times$ 240) $\mathrm{mm}$ to obtain the preform. The metal plates were covered with Teflon sheets between the interfaces of the preform (mat) and the metal plates. The metal plates served as mold, to obtain the desired preform architecture. The preform was placed in the pre-heated compression mold for the preform to gel. After about 15 minutes the preform was pressed to a pressure of about 1000 psi. Hot pressing of the preform architecture was subsequently done to about $5 \mathrm{~mm}$ and $7 \mathrm{~mm}$ thickness for the $0.5 \mathrm{~g} / \mathrm{cm}^{3}$ and $0.7 \mathrm{~g} / \mathrm{cm}^{3}$ board densities at a temperature of $130^{\circ} \mathrm{C}$ using a Carver laboratory type hot press, model number 3698 . When fully formed, the preform was conditioned to room temperature of $20^{\circ} \mathrm{C}$ and about $65 \%$ relative humidity for 24 hours and allowed to cure fully [16].

\section{Testing Procedures}

\subsection{Physical Test}

\subsubsection{Particle Size Distribution of Wood Flour}

Particle size analysis was carried out on wood particles. This was done to have an understanding of the distribution of the particles and the fraction with the greatest yield. The coarsest sieve was placed on top and the finest at the bottom. A receptacle was placed at the bottom of the finest sieve to receive the final undersize. About $200 \mathrm{~g}$ of wood flour was placed in the uppermost coarsest sieve and the 6 sieves comprising a stack was placed in an electronic automatic shaker. The total duration of the shaking process was 10 minutes. The table in the result section below shows the sieve sizes used and the corresponding weight for the undersize and oversize obtained [10].

\subsubsection{Water Resistance and Thickness Swelling Testing}

Two water resistance test specimens were cut from each panel. Water submersion tests ( 2 hours and 24 hours) were carried out in accordance with the procedure described in ASTM D1037 standard. Twenty-seven samples with varying densities were made using the compression molding process. One inch by one inch squares were cut from each sample using a ban saw. The density of the samples was calculated. Each sample group was weighed and the thickness measured to obtain initial mass $M o(\mathrm{~g})$ and initial thickness $T o(\mathrm{~mm})$. The samples were subsequently immersed in water. The weight (g) and thickness ( $\mathrm{mm}$ ) were measured after water immersion. for 2 hours, 4 hours, 6 hours and 12 hours for the first day and once a day subsequently. Sample thickness was measured with a pair of calipers with an accuracy of $0.005 \mathrm{~mm}$. The samples were dabbed with paper towel to remove surface water before the thickness and weight was measured. A Metler Toledo weighing balance with $0.005 \mathrm{~g}$ accuracy 
was used for the weight measurement [8]. The data set from the measured samples were analyzed using Microsoft excel to determine the Water absorption $W A(t)$ and thickness swell $T S(t)$ using the formula below:

$$
\begin{gathered}
W A(t)=\frac{M_{t}-M_{o}}{M_{o}} \times 100 \\
T S(t)=\frac{T_{t}-T_{o}}{T_{o}} \times 100
\end{gathered}
$$

$M_{i}$ : sample weight measured at time $(t)$; and $M_{o}$ : initial weight of sample; and $T t$ : sample thickness measured at time $(t) ; T_{o}$ : initial thickness of the sample.

Shi and Gardner model, was used to predict the water absorption rate of the nine sample groups as a function of time. The average value of the water absorption and thickness swell of the three samples in each of the group yielded the needed results [14] [15].

$$
W A(t)=\left(\frac{W_{\infty}}{W_{o}+\left(W_{\infty}-W_{o}\right) \mathrm{e}^{-K_{s r} t}}-1\right) \times 100
$$

where $W_{\infty}$ : equilibrium weight; $K_{a r}$ : water absorption rate constant.

Similarly, the thickness swelling rate was calculated based on the formula

$$
T S(t)=\left(\frac{T_{\infty}}{T_{o}+\left(T_{\infty}-T_{o}\right) \mathrm{e}^{-K_{a r} t}}-1\right) \times 100
$$

$K_{a r}$ and $K_{s r}$ was used to predict the water absorption ( $W A$ ) $t$ and thickness swelling (TS) $t$ for each time count of each sample. The accuracy of the observed data was determined using the sum of squares difference (SSD) method.

$$
S S D=\sum_{i}^{n} y_{i}-\hat{y}_{i}
$$

Model prediction unique to each sample set was developed from a regression line that was plotted from the observed data which represented the data points of each sample set. In order to create a more accurate prediction, Curve fitting technique was employed by reducing SSD to its lowest valve using the solver tool on excel. This was achieved by using $K_{a r}, K_{s r}$ and $T_{\infty}$ as variables. This provided a more precise $K_{a r}, K_{s r}$ and $T_{\infty}$ that provided a more accurate prediction of the data. Measurement of correlation function (RSQ) was also employed to check the possibility of an existing correlation between density and any of the constants $K_{a r}$ and $K_{s r}$.

\subsection{Mechanical Properties Testing}

\section{Three Point Bending Test}

The three-point bending tests were performed on a Shimadzu, Universal testing machine max weight $5 \mathrm{KN}$, AGSX series in which the upper platen was fixed and the lower platen was mobile. The composite samples having dimensions of $160 \times$ $25 \times 3 \mathrm{~mm}, 160 \times 25 \times 5 \mathrm{~mm}$ and $160 \times 25 \times 7 \mathrm{~mm}$, respectively, were used for testing. The three-point bending tests were carried out at a $5 \mathrm{~mm} / \mathrm{min}$ displacement rate. The axial force and the displacement data were recorded. For each of 
the samples at their varying densities and glass fiber percentages three samples were tested and the average values were recorded.

\section{Results}

\subsection{Particle Size Analysis}

From the results shown in Table 2 and obtained from the particle size analysis of the wood flour, it can be seen that the median distribution of the wood flour has a particle size of 150 microns and this accounted for over $54 \%$ of the entire mass of wood flour that was used.

\subsection{Effect of Board Density on Water Absorption Rate and Thickness Swell Rate}

The correlation plot for board density against $K_{a r}$ in Figure 1 shows that as the density of the material irrespective of the percentage of glass fiber inclusion increases there is corresponding decrease in the water absorption rate constant $\left(K_{a r}\right)$ with a R-squared value of 0.602 . However, the correlation plot of board density against $K_{s r}$ in Figure 2 shows a corresponding increase in thickness swelling constant irrespective of the percentage of glass fiber inclusions with a $\mathrm{R}$-squared value of 0.826 . The effect of density on the slope of the water absorption rate $\left(S_{a r}=-2 \mathrm{E}-05\right)$ is smaller compared to the effect on the swell rate $\left(S_{s r}=\right.$ $5 \mathrm{E}-07)$.

\subsection{Correlation between Absorption Rate and Swell Rate}

The plot of $K_{a r}$ against $K_{s r}$ in Figure 3 show that $K_{s r}$ increases linearly with an increase in $K_{a r}$ A positive slope and R-squared value of approximately 0.87 , indicates that there is direct correlation between both constants. It also further reflects the influence of board density on both constants.

Figure 4 and Figure 5 below respectively shows that the water absorption and thickness swelling models fit the data well. Data of material properties for water absorption and thickness swelling show that there is a strong correlation between data and model fits for WA $\mathrm{R}^{2}>0.90$ and for $\mathrm{TS} \mathrm{R}^{2}>0$.

Table 2. Particle size distribution of wood flour.

\begin{tabular}{cccccc}
\hline Sieve size & $\begin{array}{c}\text { Weight } \\
(\mathbf{g})\end{array}$ & $\begin{array}{c}\text { Weight } \\
(\%)\end{array}$ & $\begin{array}{c}\text { Nominal } \\
\text { aperture } \\
\text { size }\end{array}$ & $\begin{array}{c}\text { Cumulative } \\
\text { weight } \\
\text { (\%) undersize }\end{array}$ & $\begin{array}{c}\text { Cumulative } \\
\text { weight } \\
\text { (\%) oversize }\end{array}$ \\
\hline$+2.36 \mathrm{~mm}$ & 1.92 & 0.96 & $2.36 \mathrm{~mm}$ & 99.04 & 0.96 \\
$-2.36+1.18 \mathrm{~mm}$ & 67.83 & 33.915 & $1.18 \mathrm{~mm}$ & 65.125 & 34.875 \\
$-1.18 \mathrm{~mm}+600 \mu \mathrm{m}$ & 109.6 & 54.8 & $600 \mu \mathrm{m}$ & 10.325 & 89.675 \\
$-600 \mu \mathrm{m}+300 \mu \mathrm{m}$ & 12.6 & 6.3 & $300 \mu \mathrm{m}$ & 4.025 & 95.975 \\
$-300 \mu \mathrm{m}+150 \mu \mathrm{m}$ & 6.5 & 3.25 & $150 \mu \mathrm{m}$ & 0.775 & 99.225 \\
$-150 \mu \mathrm{m}+75 \mu \mathrm{m}$ & 0.7 & 0.35 & $75 \mu \mathrm{m}$ & 0.425 & 99.575 \\
& 0.425 & & & & \\
\hline
\end{tabular}




\section{Correlation of board density to Kar}

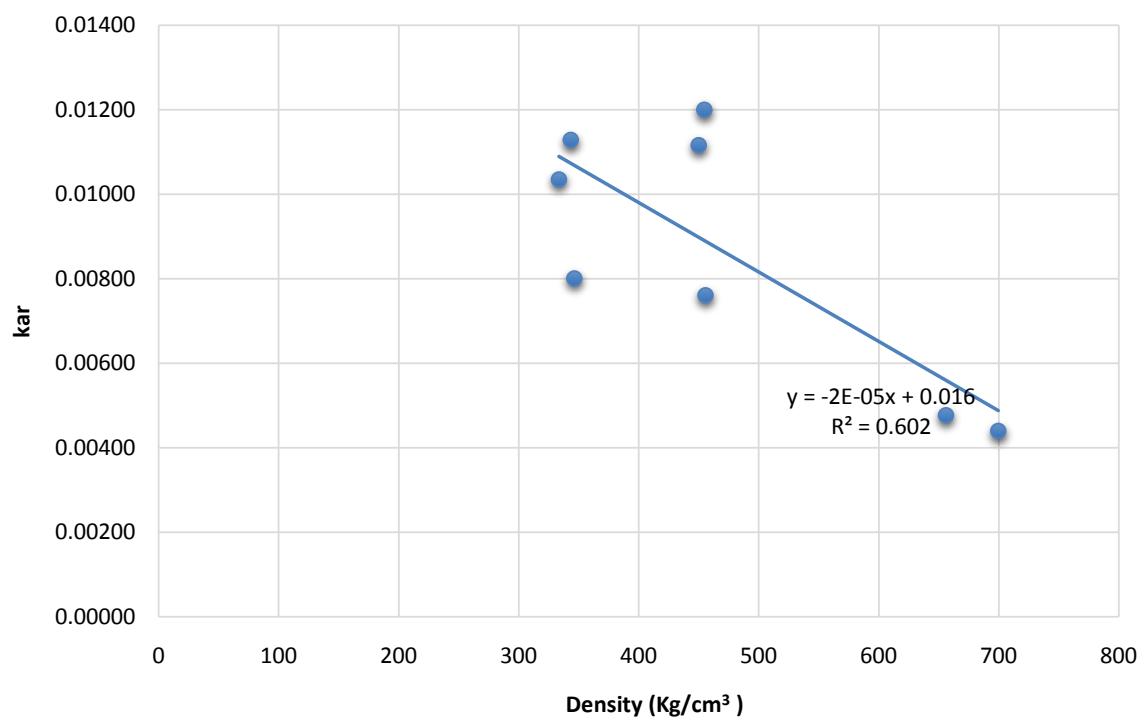

Figure 1. Correlation of board density to Kar.

\section{Correlation of board density to Ksr}

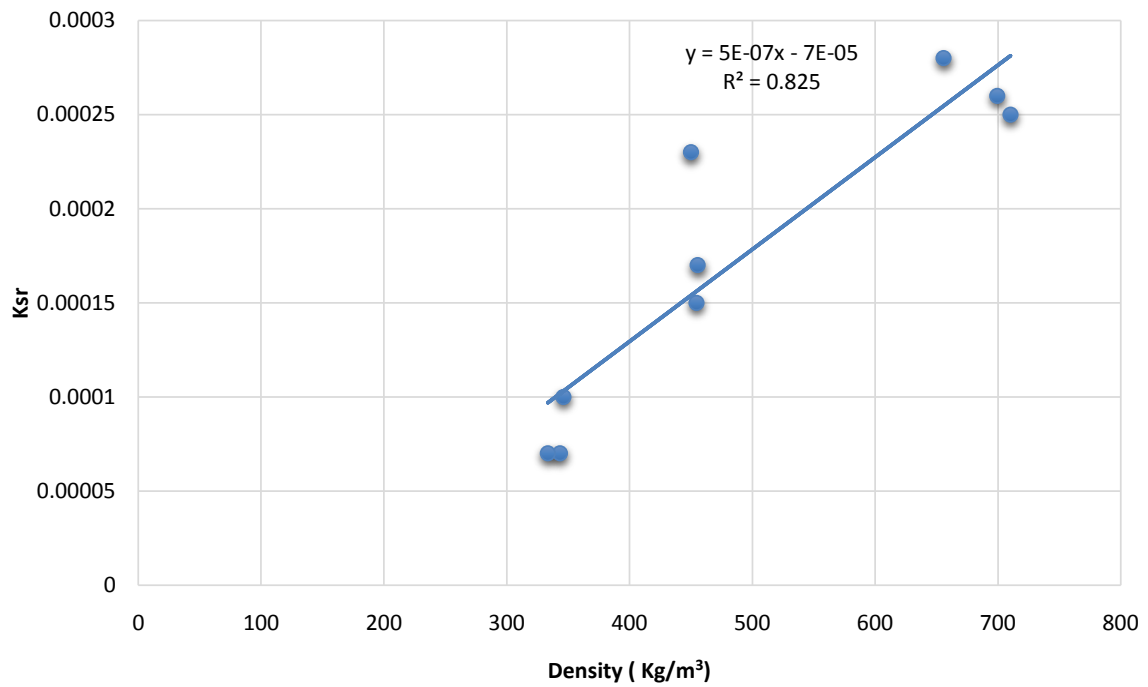

Figure 2. Correlation of board density to Ksr.

\subsection{Water Absorption Rate and Thickness Swelling Rate}

Results obtained from the investigation of the water absorption rate and the thickness swelling rate indicates that when the board samples were submerged in water containers over a period of 366 hours. As expected the $0.5 \mathrm{~g} / \mathrm{cm}^{3}$ and $0.7 \mathrm{~g} / \mathrm{cm}^{3}$ density boards with $0 \%$ recycled glass fiber inclusions had the highest rate of water absorption after 366 hours. This must have been due to the high rate of wood fiber imbibition compared to the other boards with inclusions. However, this was not the case for the $0.3 \mathrm{~g} / \mathrm{cm}^{3}$ boards, the board with $10 \%$ recycled glass fiber inclusions had the highest water absorption rate of $9.02 \%$ after 366 hours as shown in Figure 6. 


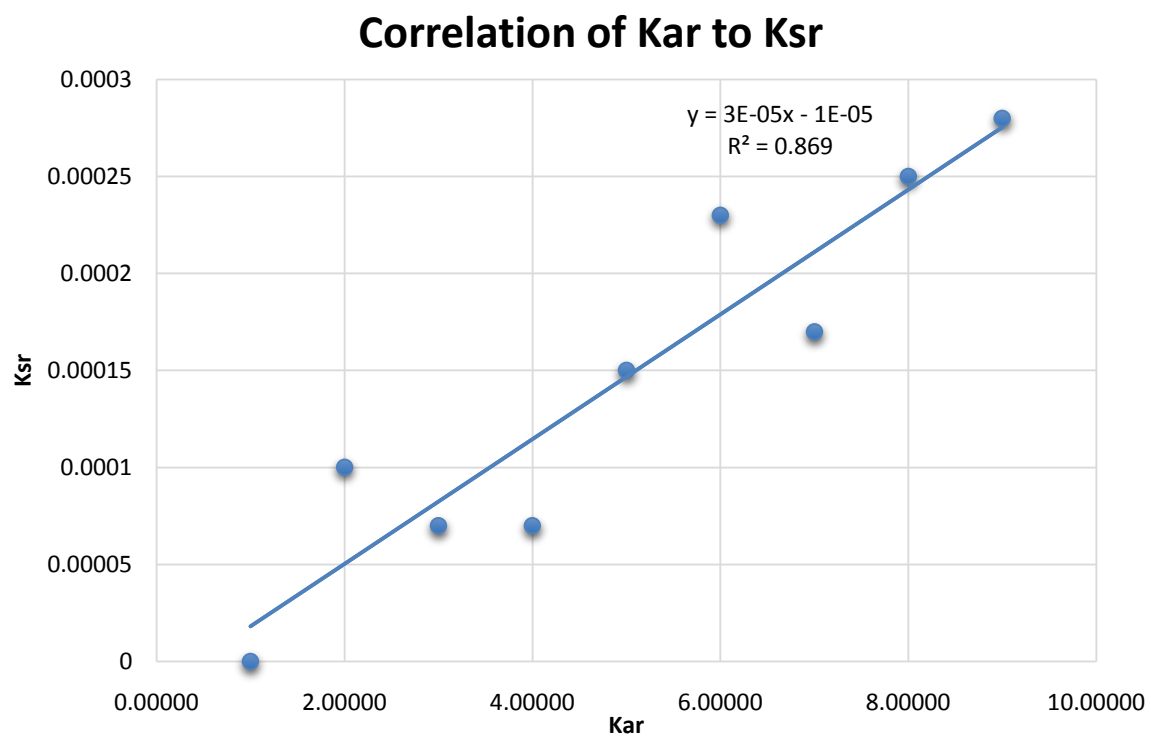

Figure 3. Correlation of Kar to Ksr.

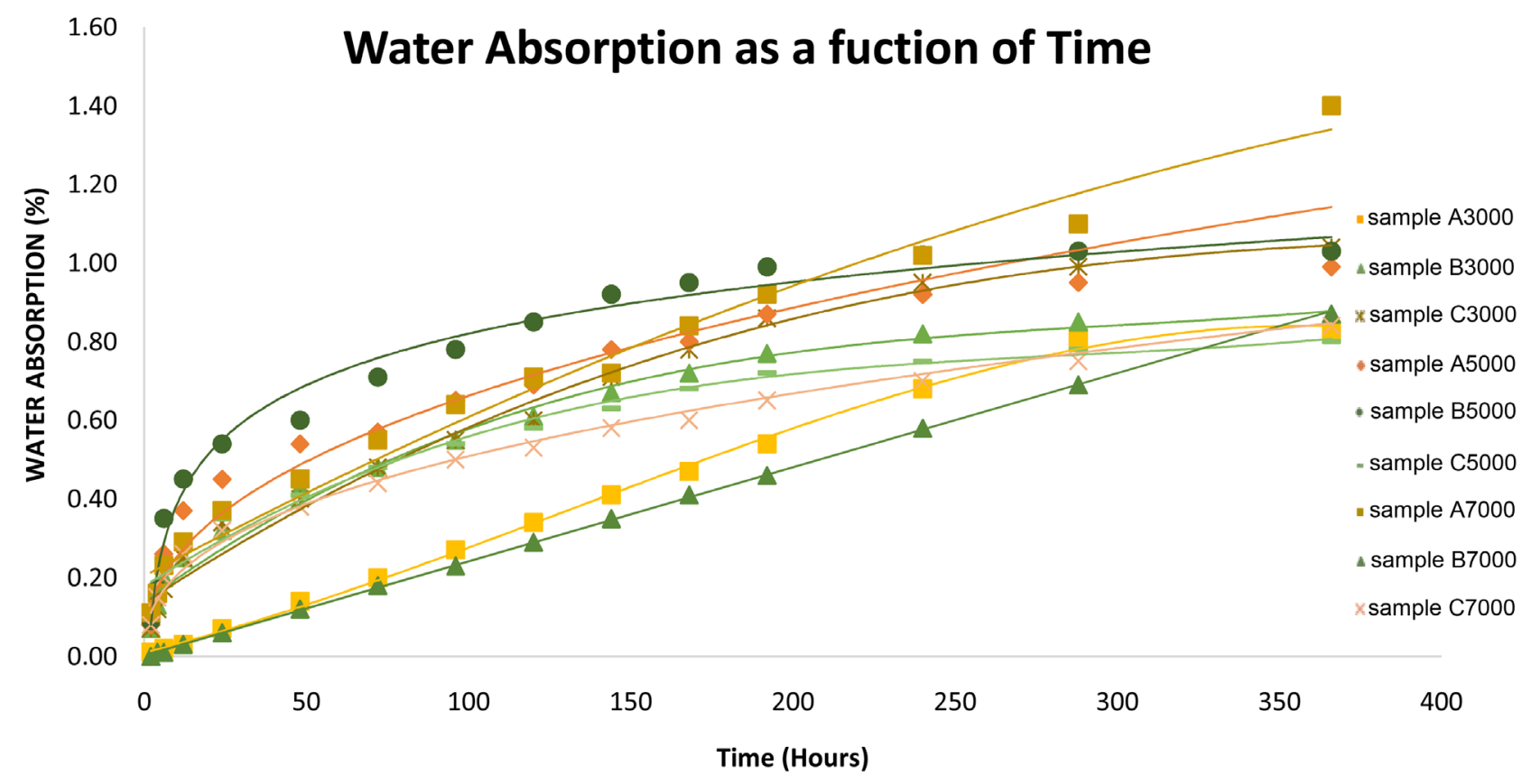

Figure 4. Plot of water absorption as a function of time.

The board types with $30 \%$ glass fiber inclusions for all densities gave high values. This is expected as shown in the plot for correlation of board density versus swell thickness that as the board density increases so also does the thickness with a positive slope of $\left(\mathrm{S}_{\mathrm{sr}}=5 \mathrm{E}-07\right)$. The $0.5 \mathrm{~g} / \mathrm{cm}^{3}$ board with $30 \%$ glass fiber inclusion had the highest thickness value of $1.4 \%$ as shown in Figure 7.

\subsection{Mechanical Properties}

Flexural Properties

The MOE and MOR values of the prepared particle-board with $0 \%$ glass fiber for 


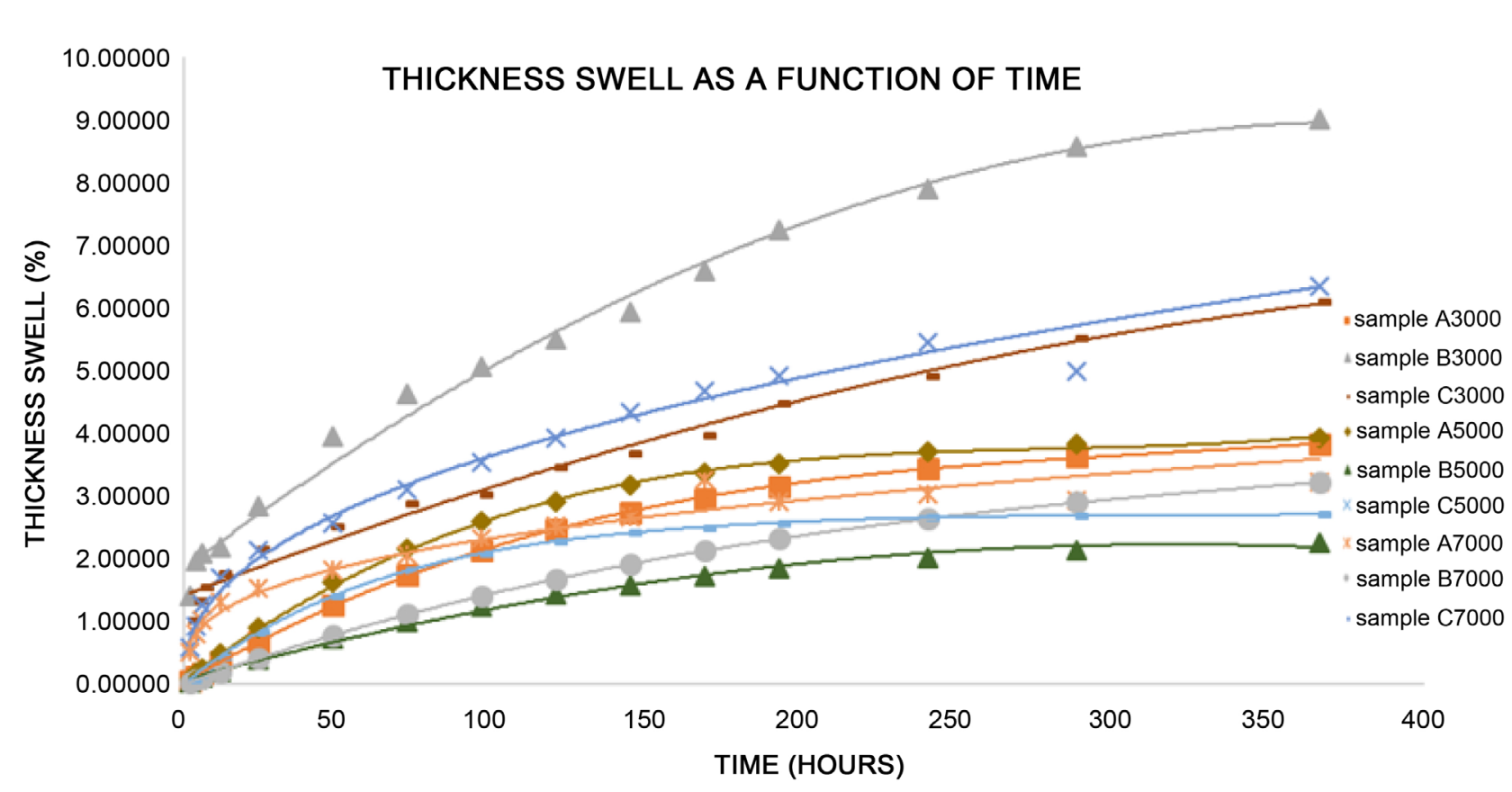

Figure 5. Plot of thickness swell as a function of time.

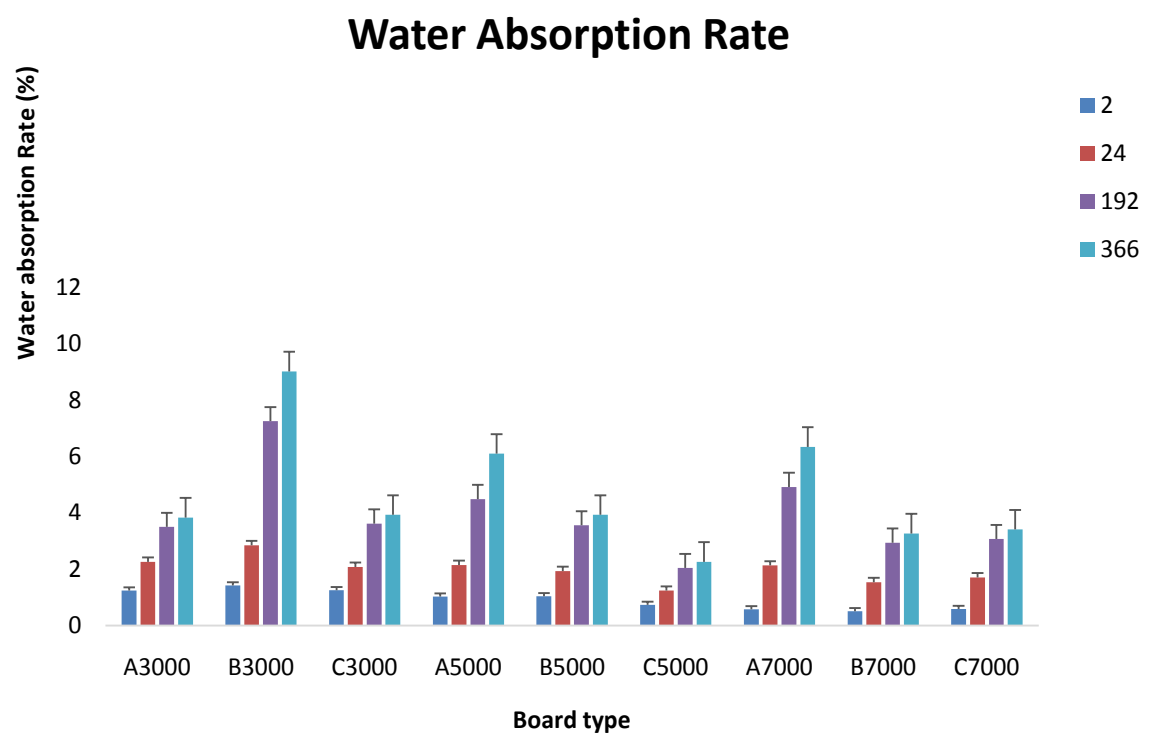

Figure 6. Water absorption rate.

the $0.3 \mathrm{~g} / \mathrm{cm}^{3}, 0.5 \mathrm{~g} / \mathrm{cm}^{3}$ and $0.7 \mathrm{~g} / \mathrm{cm}^{3}$ did not show appreciable increase when compared to the commercial particle-boards. The average MOE values of the hot-pressed particleboard are $0.328,0.358,3.42 \mathrm{GPa}$ and MOR values were 4.76, 3.1, 2.2 MPa respectively for each of the three stated densities, while the MOE and MOR of the commercial particleboard are $2.54 \mathrm{GPa}$ and $14.69 \mathrm{MPa}$ respectively. This represents a $35 \%-87 \%$ decrease and $67.6 \%-85 \%$ decrease in the MOE and MOR, respectively, this can be attributed to the presence of the epoxy system resin used as binder in making the particle board even though more environmentally friendly compared to other binders like urea formaldehyde. The 


\section{Thickness Swell Rate}

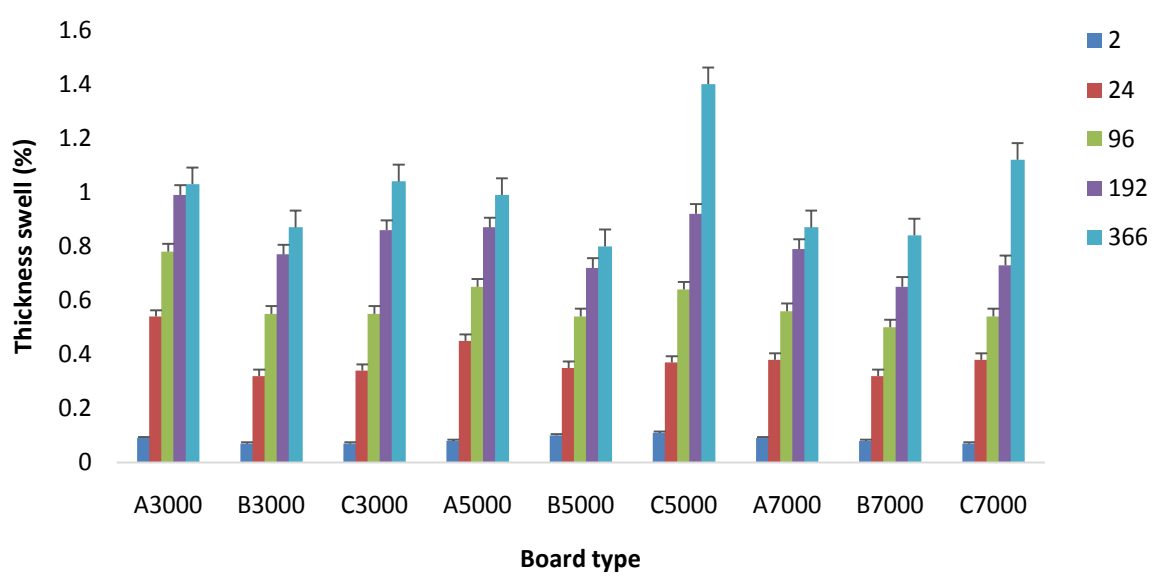

Figure 7. Thickness swelling rate.

\section{MOE (GPa) and MOR (MPa)}

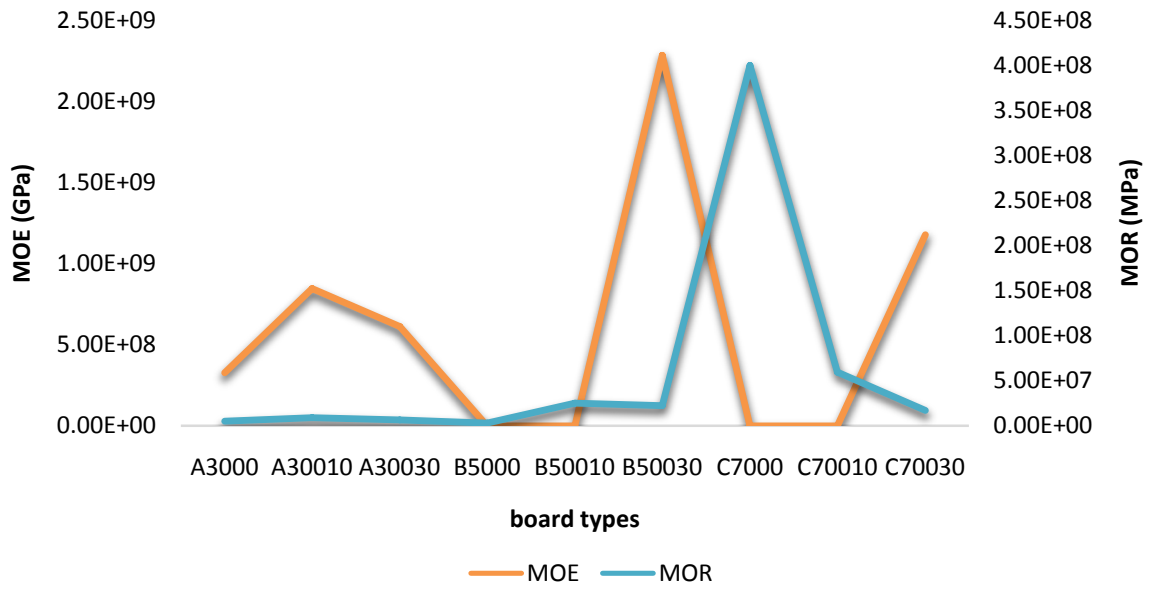

Figure 8. Plot of MOE (GPa) vs. MOR (MPa).

heavily cross-linked structure leading to brittle behavior and poor resistance to crack initiation and growth thus causes low toughness and impact resistance which decreases mechanical performance [15]. The effect of adding different ratios of short glass fibers to the wood particles was investigated. The average MOE and MOR values of the particleboard with $10 \%$ recycled glass fibers for each of the three densities was $0.85,0.89$ and $2.54 \mathrm{GPa}$ respectively, while the MOE values for the $30 \%$ glass fiber inclusions for each of the three densities was $0.61,2.29$ and $1.18 \mathrm{GPa}$. For the $10 \mathrm{wt} \%$ there was an increase of over $80 \%$ in MOE values for $0.5 \mathrm{~g} / \mathrm{cm}^{3}$ and $0.7 \mathrm{~g} / \mathrm{cm}^{3}$ densities respectively. However, there was a decrease in MOE value for the $30 \mathrm{wt} \%$ glass fibers for the particle board of both densities. This suggests that an increase in density does not necessarily translate into an increase in MOE values. For the MOR values, there was an increase of over $84.4 \%$ in value for both densities and glass fiber inclusions. Plot showing the interactions between MOE and MOR is as shown in Figure 8. 


\section{Conclusions}

1) The water absorption (WA) and thickness swelling (TS) models fit the data well with WA $\mathrm{R}^{2}>0.90$ and for TS $\mathrm{R}^{2}>0$. This shows that both models are good predictors of hygroscopic swelling process of wood flour reinforced with recycled glass fibers.

2) There is a direct correlation between the absorption rate $K_{a r}$ constant and the swell rate constant $K_{s r}$ As the absorption rate increases, so does the swelling rate increase correspondingly. This is also a function of the density of the board. Correspondingly, hybrid composite boards with higher densities record higher values than lower density hybrid composite boards.

3) A poor relationship was found between an increase in percentage of glass fibers for various board densities and the corresponding MOE and MOR values. This implies that there is no corresponding arithmetic progression for MOE and MOR values as the percentage of glass fibers inclusion increases. However, the overall trend shows that the inclusion of glass fibers in boards produces an improvement in MOE and MOR values when compared with particle-boards with no glass fiber inclusions.

\section{References}

[1] Pico, D., Wilms, C., Seide, G., Gries, T., Kleinholz, R. and Tiesler, H. (2012) "Glass Fibers" Ullmann's Encyclopedia of Industrial Chemistry. Fibers, 12. Wiley-VCH Verlag GmbH \& Co. KGaA.

[2] Bartl, A. and Pico, D. (2009) Characterization of Short Fibers. The 9 th International Conference on Chemical and Process Engineering, Tsukuba Science City, 14.

[3] Pimenta, S. and Pinho, S.T. (2011) Recycling Carbon Fibre Reinforced Polymers for Structural Applications: Technology Review and Market Outlook. Waste Management, 31, 378-392. https://doi.org/10.1016/j.wasman.2010.09.019

[4] Juliana, A.H., Paridah, M.T., Rahim, S., Azowa, N.I. and Anwar, U.M.K. (2012) Properties of Particleboard Made from Kenaf (Hibiscus cannabinus L.) as Function of Particle Geometry. Materials and Design, 34, 406-411. https://doi.org/10.1016/j.matdes.2011.08.019

[5] Tabarsa, T., Ashori, A. and Gholamzadeh, M. (2012) Evaluation of Surface Roughness and Mechanical Properties of Particleboard Panels Made from Bagasse. Composites: Part B, 42, 1330-1335. https://doi.org/10.1016/j.compositesb.2010.12.018

[6] Wechsler, A., Zaharia, M., Crosky, A., Jones, H., Ramírez, M., Ballerini, A., Nuñezc, M. and Sahajwalla, V. (2013) Macadamia (Macadamia integrifolia) Shell and Castor (Rícinos communis) Oil Based Sustainable Particleboard: A Comparison of Its Properties with Conventional Wood Based Particleboard Materials and Design, 50,117-123.https://doi.org/10.1016/j.matdes.2013.03.008

[7] Hassanin, A.H., Hamouda, T., Candan, Z., Kilic, A. and Akbulut, T. (2016) Developing High-Performance Hybrid Green Composites. Composites Part B: Engineering, 92, 384-394. https://doi.org/10.1016/j.compositesb.2016.02.051

[8] Smith, L.M. and Shi, S. (2015) Hygroscopic Performance of VARTM Kenaf Bast fibers Reinforced Epoxy Resin Composites. Journal of Chemical Engineering and Chemistry Research, 2, 780-788.

[9] Holt, G.A., Chow, P., Wanjura, J.D., Pelletier, M.G. and Wedegaertner, T.C. (2014) 
Evaluation of Thermal Treatments to Improve Physical and Mechanical Properties of Bio-Composites Made from Cotton by Products and Other Agricultural Fibers. Industrial Crops and Products, 52, 627-632.

[10] ASTM (2012) Standard Test Methods for Evaluating Properties of Wood-Base Fiber and Particle Panel Materials. America Society for Testing and Materials, West Conshohocken, PA.

[11] Goswami, D.N., Ansari M.F., Day. A., Prasad, N. and Baboo, B. (2008) Jute-Fiber Glass-Plywood/Particle Board Composite. Indian Journal of Chemical Technology, $15,325-331$.

[12] Shi, S.Q. and Gardner, D.J. (2005) Hygroscopic Thickness Swelling Rate of Compression Molded Wood Fiberboard and Wood/Polymer Composites. Composites: Part A, 37, 1276-1285.

[13] Shi, S.Q. and Wu, D.F. (2009) Modeling Moisture Absorption Process of Wood-Based Composites under Over-Saturated Moisture Conditions Using Two-Part Equations. Wood Science and Technology, 43, 143-152. https://doi.org/10.1007/s00226-008-0201-x

[14] Chen, J., Kinloch, A.J., Sprenger, S.A. and Taylor, C. (2013) The Mechanical Properties and Toughening Mechanisms of an Epoxy Polymer Modified with Polysiloxane-Based Core-Shell Particles. Polymer, 54, 4276-4289.

[15] Faola, A.E., Oladele, I.O., Adewuyi, B.O. and Oluwabunmi, K.E. (2013) Effect of Chemical Treatment on Water Absorption Capability of Polyester Composite Reinforced with Particulate Agro-Fibers. Chemistry and Materials Research, 3, 106-112. http://www.iiste.org

[16] Elbadawi, M., Osman, Z., Paridah, T., Nasroun, T. and Kantiner, W. (2015) Mechanical and Physical Properties of Particleboards Made from Ailanthus Wood and UF Resin Fortified by Acacias Tannins Blend. Journal of Materials and Environmental Science, 6, 1016-1021. 